\title{
Volunteering - An Efficient Collaborative Practice for the Local Communities Sustainability. Empirical Study
}

\author{
Daniela Predețeanu-Dragne ${ }^{1}$, Dan Popescu ${ }^{2}$ and Valentina Nicolae ${ }^{3}$
}

\begin{abstract}
The scientific research we have conducted concerns volunteering as a collaborative practice and as a basis for the sustainable development of local communities. Identifying the suitable practices capable of transforming a group of individuals into a prosperous and sustainable collaborative community has became our priority concern. Therefore, the main objective of the study was outlined as a response to the question: "which are the tangible and intangible effects of the acts and facts of the collaboration identified in the communities where the participants in the study came from?". The answer was prefigured as the outcome of an exploratory analysis that also revealed to us the motivation, satisfaction and results obtained by the participants in the survey, as a consequence of their personal experience in relation to their community. The quantitative analysis of collected data was performed in IBM SPSS software and the qualitative analysis with the Atlas Ti application. Despite the poverty of information sources in the field, our exploratory research has succeeded in highlighting the role of volunteering as a factor of sustainable social cohesion and practice in local communities. And this is at least one of our reasons useful to continue our theoretical and applied researches related to the emergence and sustainable development of collaborative communities.
\end{abstract}

Keywords: exploratory analysis; collaborative community; sustainability; social economy enterprise; social innovation

\section{Introduction}

This paper has the role to identify the representative factors of economic collaboration in local communities through a qualitative analysis focusing on tracking the effects of volunteering in local communities sustainability.

Regarded as a catalyst of social actors, volunteering is a confirmed factor of collaboration [1], with a clearly defined role in community cohesion [2], as well as the generator of the trust capital established among members [3], the long-term direct and foreseeable consequence being the sustainable creation of responsible communities.

Participation in volunteering, individually or in an organized framework [4] facilitates the development of collaborative comprehensive, sustainable and synergistic communities, capable of working with the people and of engaging creativity in order to identify viable solutions to daily socio-economic problems [5].

The transition to a prosperous and sustainable community is not achieved by going down the same path that was taken in a vulnerable situation but, on the contrary, by looking beyond the usual behaviour and attitudes and identifying different opinions, visions and behaviours [6], followed by their analysis and adaptation to the context. For the sake of this transition, which we want translated into reality as soon as possible, we believe that the time has come for us to restore the place of volunteering in the community, since it is a known fact that the collective memory of the inhabitants of an ex-communist country such as Romania (at least the memory of the middle-aged 
generation) does not see volunteering in a very favourable light. We see and we feel more aware than ever of how rapidly the world changes around us [7]. The generation change comes with a new culture of volunteerism where young people (mostly undergraduate students) assume volunteering behaviours for various reasons $[8,9]$.

Participation in volunteering activities results in at least a double gain: on the one hand, the cause itself wins, and on the other hand the people who contribute to its realization also win. Interacting with new people who have initiative, citizenship and common interests promotes social cohesion and fosters the emergence of collaborative communities germs [10].

The social economy enterprise is the ideal place in which volunteering can be experienced as a collaborative and sustainable practice within a community [11-15]. The organizational framework offered by these entities provides the volunteers involved in socio-economic community projects with the possibility of gaining collaborative experience in order to achieve the objectives.

Undoubtedly, collaboration as a life lesson is best learned starting from childhood, without any age limit for learning. Collaboration is learnt simultaneously with individual responsibility. Encouraging experiential learning is also a vibrant, engaging alternative of formal learning, which, as the society evolves - facilitated by the information technology -, is considered by many young people as boring or even uninteresting [16-18].

Economic and financial crises are more and more often considered to be a progress factor, especially technical and technological, as well as periods that favour social change by changing mentalities. Similarly, the collaborative community that emerges around social economy enterprises constitutes a viable and sustainable solution, able to counteract the effects associated with these crises, volunteering being the active and participatory factor which generates change.

\section{Literature Review}

At European level, social economy enterprises are seen as economic operators combining entrepreneurship with social objectives, their priority being the social impact [19-21]. They achieve their objectives through a responsible management, by involving the employees, the consumers and the shareholders. The European Commission uses the term "social enterprise" for the business whose commercial activity has the purpose to achieve a social or societal goal, for the common good [22].

In our perception, the common good involves collaboration as a participatory and responsible action of the community, both in the form of social involvement and in order to achieve punctual and sustainable economic objectives, the players involved in social economy enterprises having an even bigger role to play in this respect.

The consequence of collaboration, as a conscious action, is that of forming the collaborative community, whose trust capital becomes the glue of interpersonal relationship and the main source of sustainable development.

The theoretical and methodological approaches to collaborative community are only at the beginning. Thus, the documentary search that we did on the Google Scholar platform for the phrase "collaborative community" initially returned 16,500 results worldwide, mostly in articles. 
As a consequence of filtering the search results by the "collaborative community" thematic area and management as a field of interest, 9 items were returned (Table 1).

Table 1. Relevant peer-reviewed literature indexed in the Google Scholar database regarding the collaborative community, by year

Ref. Approaches

\section{Leadership Education - 1 article}

The study addresses the issue of community health partnerships, advancing the idea that leadership

[23] in partnership differs from the traditional, hierarchical one, by the fact that the participation is voluntary, egalitarian and it often involves collaboration between organizations with different agendas and cultures.

Thus, new challenges appear regarding the formal control over the members.

\section{Professional Learning Community - 1 article}

The study treats the school as a community of collaboration aimed at professional learning and

[24] addresses the issue of the availability of teachers to work together for continuous school improvement and, by extension, for improving student achievement.

\section{Corporate Analysis - 1 book}

The study focuses on corporations which have been characterized in recent years by a strong corporate [25] paternalism.

The second subject debated is the need for collaboration, teamwork and the danger of losing the loyalty and commitment of employees.

\section{Community Analysis - 1 book}

This paper explores the changing nature of communities in modern corporations. The community of companies, which relied on loyalty, has been largely destroyed by the economic turmoil of recent years.

[26] The community is becoming increasingly important in an increasingly complex knowledge economy.

A new form of community - collaborative community - is developing.

\section{Business Community - 1 article}

The paper analyses a community of companies created as an online platform in order to develop an

[27] innovative technology of the computer - server type. The community of companies is designed in order to take over some of the basic functions and processes of a community of individuals.

\section{Management Practices - 1 article}

The public management of natural resources requires, according to the approach of the authors of the article, the establishment of collaborative communitarian groups capable to develop and support new

[28] organizational structures, processes and strategies.

A framework is presented for assessing of collaborative capacity, in relation to the management of US public forests, given that there appears to be a lack of understanding of the elements which make the collaboration possible.

\section{Community Engagement - 1 article}

The paper describes the decision-making process for developing the water management strategy in

[29] Canterbury. This process was designed to be dynamic in order to work with the stakeholders and to involve the community.

\section{Collaborative Community Governance - 1 article}

While trying to answer the question: "How does collaborative governance work at community level?", the study

[30] aims at developing a model of collaborative governance as an integrative framework with a set of evaluation criteria to review the governance of communitarian collaborative practices which are being developed in Korea.

\section{Tourism - 1 article}

The study examines the perceptions and attitudes of the residents of an island towards tourism development and integration of the community in tourism planning. The results show that the residents

[31] believe that tourism planning should be more sensitive to the residents and to tradition, and able to guarantee a higher level of protection of the heritage.

Source: Documentary analysis conducted by authors 
In order to identify the relevant papers for the collaborative community field of study, we have expanded the search on the Scopus platform, known as a database notoriously dedicated to peer-reviewed literature. Our initial search returned 537 papers indexed and, after restricting the domain of interest to "Business, Management and Accounting" 37 papers were returned, which are published in social economy and political economy journals (Figure 1).

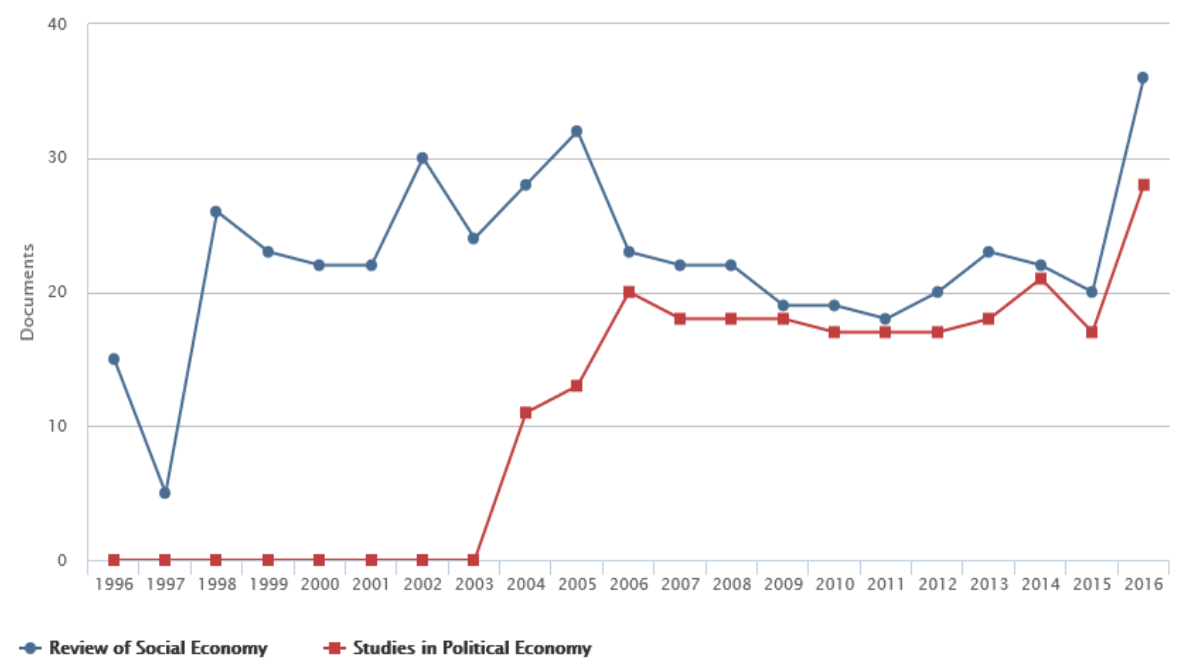

Figure 1. Collaborative community - Studies indexed on the Scopus database, in the "Business, Management and Accounting" domain. Source: Authors, based on the survey.

Refining the search by the keywords used by the authors of the papers, the reputation of the journal that published the study and the existence of an abstract (as a minimum condition), led us to the possibility of classifying the fields of study addressed to date (Figure 2) relative to countries in which, as a rule, the studies were conducted (Figure 3). The graphic representation in Figure 3 indicates the fact that the collaborative community is an extremely generous field of study.

A first classification of the documents divided the published studies into five categories: management, education, community, business and other areas including medicine and security (Figure 2), each category highlighting a specific type of existence and manifestation of the collaborative community.

A particular form of collaborative community, specific to the digital era, is crowdsourcing; it is among the techniques that organizations resort to more and more often (Apple and Wikipedia are just two illustrative examples) in order to receive help in solving innovation and research issues $[32,33]$. Another form of collaborative community, bearing the imprint of the digital age, are the networks of enterprises, constituted as a form of social network with a view to promoting sustainable collaboration by providing services within an organization [34] or by maintaining the online presence in their relations with customers and investors [35]. 


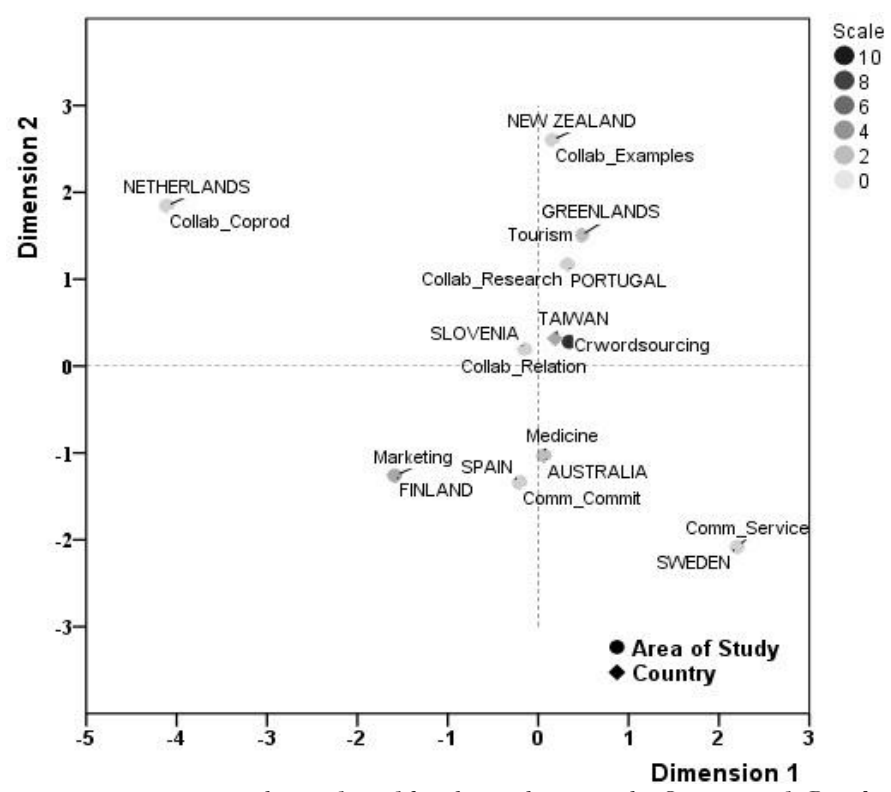

Figure 2. Documentary systematic research, conducted by the authors, in the Scopus and Google Scholar database. Data processing in Atlas.ti
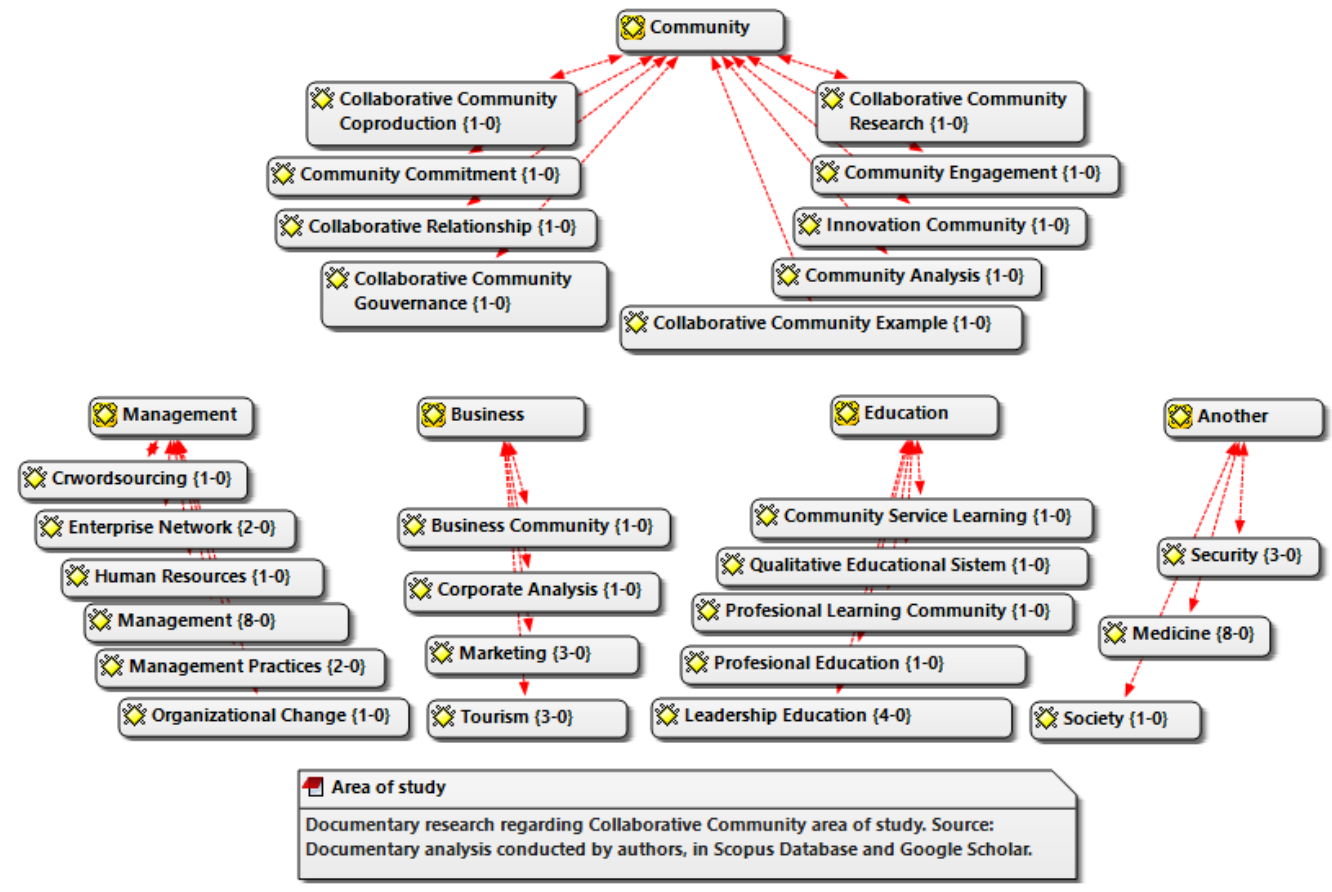

Figure 3. Fields of study on "collaborative community" identified in the Scopus database.

Source: Data processing by the authors, in SPSS 
The Innovation contest community as a specific form of community and as a particular interaction phenomenon [36] built on the competition principle, but also having the advantages of a collaboration community is highlighted in the paper "Reciprocity vs. FreeRiding Contest in Innovation Communities".

The main directions of development of the organization of professional work are the subject of the article entitled "Professional work: The emergence of collaborative community" [37], which underlines that the principles of market economy and the hierarchy become increasingly prominent in the professional work to the same extent to which the influence of professional community principles is increasing.

The topic of collaborative communities is tackled in the Frieling, Lindenberg and Stokman article's "Collaborative Communities Through Coproduction: Two Case Studies" [38] which aims at presenting a method of cooperation between residents and specialists with the purpose of improving the living conditions in the neighbourhood, called by the authors the coproduction method (3C). Among other aspects, the three authors identify the dilemma of sustainable cooperation as an additional challenge of citizen participation, for the solving of which they conceive the " $3 C$ method" as a continuous, circular process of elaboration, implementation and evaluation of the plan.

The need to expand the cooperation relations in the automotive industry is highlighted in the article "Now or never: the automotive collaboration imperative" [39]. According to the authors, the success depends on adopting a model based on collaboration relationships with the suppliers and other partners; the companies which can quickly connect to the best supply communities and which will be able to accelerate consumer-based innovation will prevail.

The article "Destination social business: Exploring year organization's journey with social media, collaborative community and expressive individuality" [40] advances the idea that a modern and a sustainable company tends to be organized like a community, in accordance with the collaboration principle, within which the organizational structure is not redundant, but it must be complemented by the collaborative community in response to market demands.

"Removing barriers: Using a PDS model to enable collaborative community and school partnerships to serve at-risk students" [41] is a comprehensive work which has, among others, as a direction of study how to achieve successful partnerships in school networks. It presents the leverage produced by the combination between the resources of the local community and a training programme for teachers and the local schools, when after-school support programmes are developed and implemented for at-risk students.

The last paper we will focus on in this chapter, the topic of which we consider to be a support for the main objective of our study, is the article "Leadership and power in fostering a collaborative community in a non-profit professional organization", a research study conducted by Githens [42] in a volunteers' organization, whose objective was to build a collaborative community. The difficulty and, in fact, the main challenge encountered by the volunteers, was to establish the power roles within the group while developing the collaboration community.

\section{Objectives, Hypotheses and Work Methodology}

The social economy enterprise is a collaborative community in itself, as well as an 
integral part of the community in which it operates, without being a substitute thereof. The trust relationship becomes an intangible social contract among the community members.

The main objective of our work is to bring further information on the ability of the participants in the study to work together to achieve some well-defined goals for the benefit of the communities they live in, briefly to identify the collaboration as a presence in local communities. In order to achieve our objective, we investigate the members of a stable micro-community which we have observed since 2002, on the willingness to engage in volunteer work. We continue to study in the same micro-community from August 2015 on the degree of knowledge of the social economy, in which we highlighted that the social economy sector (including social economy enterprises as representative organizations) was very little known at that date.

Our curiosity started from the desire to check the veracity of the results a qualitative analysis which can confirm, nuance or deny the existence of the defining factors of collaboration and collaborative practices existing in Romanian local communities. Thus, the main objective of the paper was outlined in response to the question: What are the tangible and intangible effects of the acts and facts of collaboration identified in the communities where the participants in the study came from? Additionally, a new question arises, which, as researchers we cannot ignore: how are the collaborative volunteer activities recorded in the collective memory of Romanian communities?

The answers emerged during the exploratory analysis, qualitative by excellence, which we made in order to nuance attitudes and practices of cooperation and mutual trust established in Romanian local communities and also the motivation, emotions, perceptions, feelings which lead the participants in the study to get involved in community life.

Our approach is based on the assumption that the reality perceived by each participant in the study has its own dynamics, influenced by education, living environment, cultural level, access to new technologies, religion, beliefs etc., with a direct impact on the motivation and decision to be (or not to be) part of a collaborative community (family, school, working group, initiative group, social economy enterprise, etc.).

The work methodology - presented in Table 2 -, consists in conducting a survey using a semistructured questionnaire from which we selected for analysis the answers to three questions concerning the involvement of the participants in the study in volunteering, as follows:

1. Which is the greatest satisfaction that you have attained through participation in volunteering activities?

2. Can you tell us what motivates you to continue volunteering?

3. Can you tell us which is the most beautiful story of an achievement obtained through your own efforts? In this way, we are exploring the effects of volunteering as a representative factor of the impact of collaborative practices in local communities, as identified in the previous study.

We believe such an approach is useful, on the one hand, to in order to give the participants in the study complete freedom to express themselves, using their own words and natural way of thinking and feeling and, on the other hand, to capture the dynamics of the events [43]. 
Table 2. Research Methodology

\begin{tabular}{ll}
\hline Type of research: & Qualitative research \\
\hline Research method: & Survey \\
\hline Primary data collection instrument: & Semi-structured Questionnaire \\
\hline Sampling method: & Mixed Methods; the dominant one being the snowball technique \\
\hline Sample size: & 257 people \\
\hline Target group: & Romanians nationals and Romanians in the diaspora \\
\hline Place of deployment: & Romania \\
\hline Method of analysis: & Qualitative data analysis \\
\hline Data collection period: & $\begin{array}{l}\text { The research is still in progress, the questionnaire is available online at: } \\
\text { http://www.goo.gl/forms/eUWK17 XLLQ/ }\end{array}$ \\
\hline Data processing: & Atlas Ti and IBM SPSS applications \\
\hline
\end{tabular}

Source: Synthesis realised by the authors

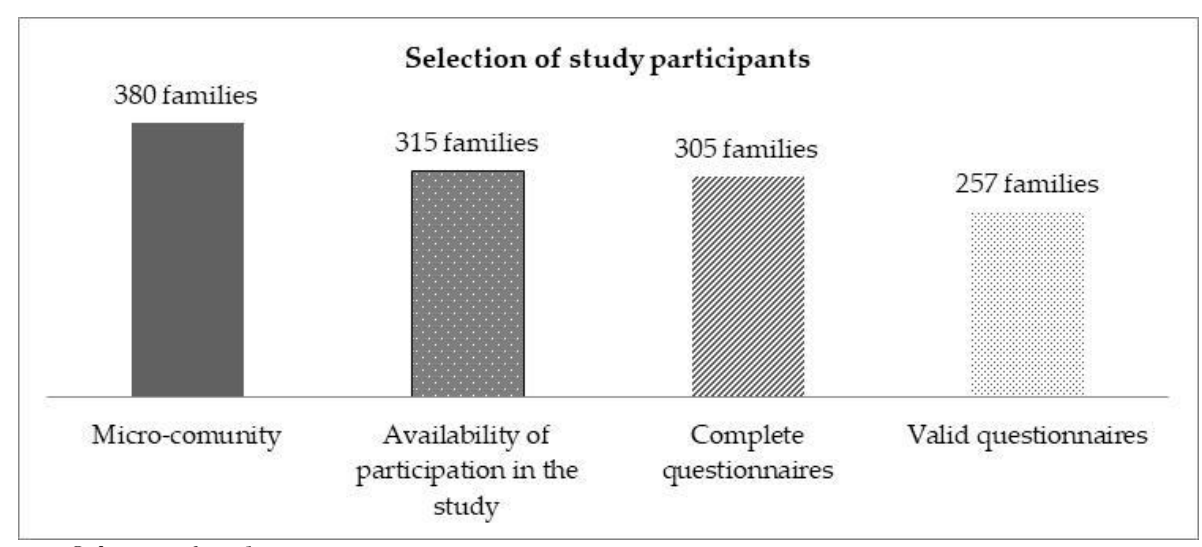

Figure 4. Selection of study participants

\section{Results}

The interpretation of the results obtained from processing the data collected through the questionnaire is performed with the Atlas Ti application for the qualitative analysis and the IBM SPSS to characterize the sample.

1. The basic statistical inventory is performed for the Gender and Education variables (Table 3). The analysis is performed on 257 subjects without any missing subject. The sample consists of 157 males (range minimum 1) and 100 females (range maximum 2). 228 subjects, representing $88 \%$ of the survey participants are graduates of higher education institutions, of which 32 subjects, representing $12 \%$ of all survey participants, are graduates of doctoral studies (range maximum 5).

Table 3. Statistics

\begin{tabular}{llcc}
\hline & & Gender & Education \\
\hline \multirow{2}{*}{$\mathrm{N}$} & Valid & 257 & 257 \\
\cline { 2 - 4 } & Missing & 0 & 0 \\
\hline Range & 1 & 4 \\
\hline Minimum & 1 & 1 \\
\hline Maximum & 2 & 5 \\
\hline
\end{tabular}


Education * Gender Crosstabulation

\begin{tabular}{llccc}
\hline \multirow{2}{*}{ Count } & & \multicolumn{2}{c}{ Gender } & \multirow{2}{*}{ Total } \\
\cline { 3 - 4 } & Male & Female & \\
\hline \multirow{3}{*}{ Education } & Primary School & 1 & 2 & 3 \\
\cline { 2 - 5 } & Secondary Education & 17 & 9 & 26 \\
\cline { 2 - 4 } & University Studies & 34 & 75 & 109 \\
\cline { 2 - 5 } & Postgraduate & 31 & 56 & 87 \\
\cline { 2 - 4 } & Doctorate & 17 & 15 & 32 \\
\hline Total & & 100 & 157 & 257 \\
\hline
\end{tabular}

Source: Data processing, by the authors, in SPSS

The need to complete the range of subjects, through enrolment of all the representative segments of the Romanian society, has led us to expand the sampling to the segment represented by high school students, whose final level of study completed is primary school (range minimum 1).

\section{Quantitative analysis of recorded data}

Of the total participants in the study, 46 were unable (or unwilling) to provide a response on the satisfaction that they have obtained by participating in volunteering activities, 25 did not provide an answer regarding the motivation to continue volunteering activities and 57 subjects were unwilling to share their most beautiful story regarding the achievements obtained by their own efforts.

\section{Qualitative, content analysis of recorded data}

The qualitative analysis is conducted according to the following work algorithm:

a) identifying the representative categories of the recorded responses;

b) encoding the recorded responses;

c) identifying the relationships established between codes;

d) assessment of the effects of cooperation through volunteering activities, as expressed by the participants in the survey.

a) the classification of the recorded responses is made according to the volunteering effects generated in the community (Figure 4). We identified 12 representative categories, each representing as many specific forms of cooperation, which will be presented in alphabetical order, in order not to diminish their importance:

- Self-realization; integration in the community;

- As a gesture of normality;

- Cohesion, cooperation and reciprocity;

- Conditioning;

- The desire to make a profound change in the community;

- The need to be useful;

- Did not understand the questionnaire;

- Does not want to participate in volunteering activities in the community;

- For the benefit of the community;

- Training tomorrow's generation;

- Achievement of objectives, results obtained;

- Social change.

b) the encoding of the recorded responses is performed in the Atlas Ti application, using the criterion: the motivation of participants in the study to actively participate in community 
life. This resulted in 12 distinct families of codes (http://www.atlasti.com/manualsdocs/) as follows (Figure 5):

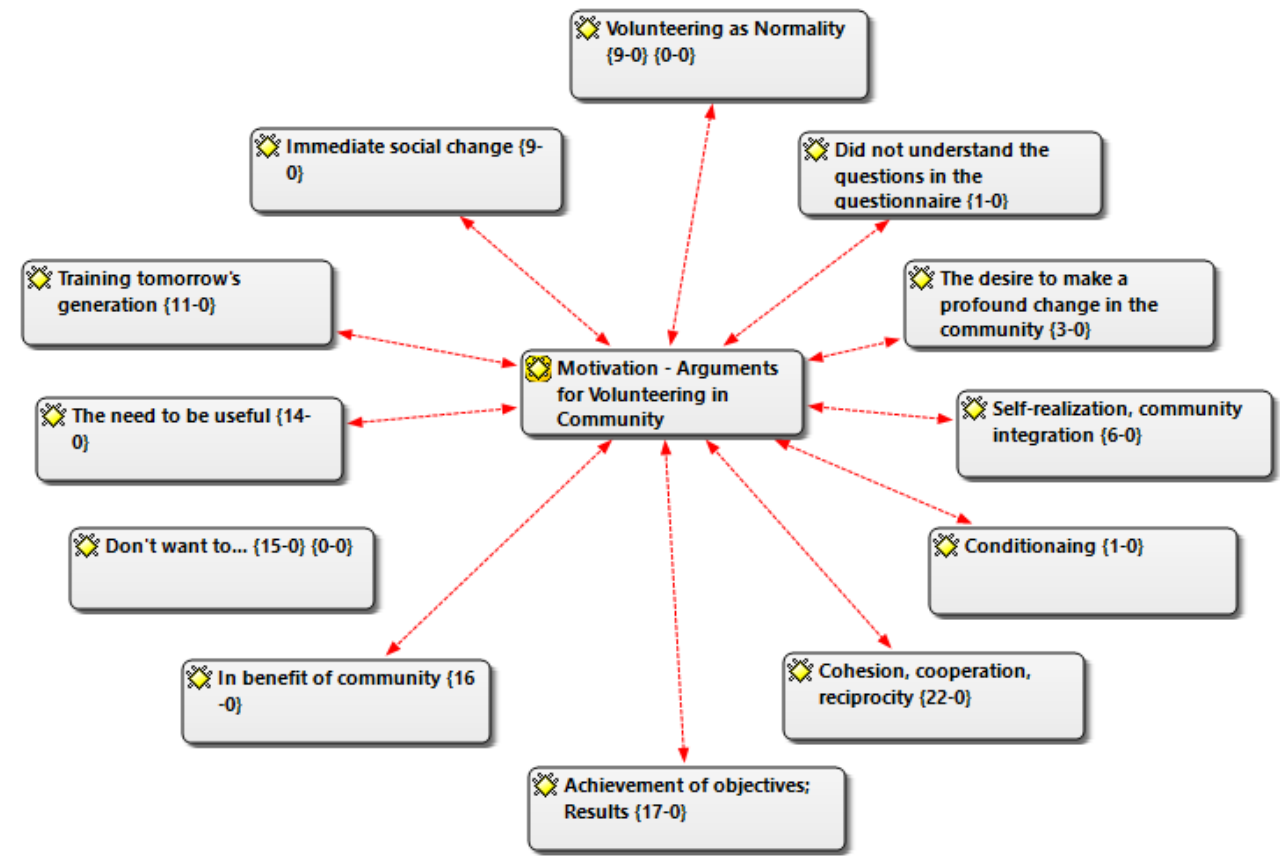

Figure 5. The classification of recorded answers.

Source data processing, by the authors, in Atlas Ti

c) in order to highlight the relationships established among the three elements of the equation: motivation - satisfaction - achievements, we have established as a central element the motivation of the participants in the study to participate in volunteering activities. Using the "association" function ( $<$ is Associated with $>$ ) we have stated the relationship between motivation - satisfaction and, using the "causal" function (<explains $\rangle$ ) we have stated the relationship between motivation - achievements (Figure 5).

d) assessing the effects of cooperation through volunteering, identified in the resident communities of the participants in the study is set forth in the positive dynamics of data processing, in order to highlight the causes, not negligible at all, which can block or restrict the collaboration of individuals in a community, as well as the beneficial effects produced when performing this action. Within this context, 13 responses were identified ( $5 \%$ of total responses recorded), which represent as many (credible) arguments for noninvolvement in voluntary activities (Table 4) as follows:

- it is not worth it to participate in voluntary activities $([1: 13])$,

- disrespect for social involvement ([1:7] Volunteering is not respected and appreciated by the vast majority of society members),

- indifference of beneficiaries ([1:8] I am not willing to work for others who are doing nothing but only complain and they cannot even understand why it happens that someone else is doing something for them. They constantly have the feeling that they deserve that someone should take care of them.),

- lack of reciprocity from the community ([1:1] As long as the community does not do anything for me, 
why would I do something for the community?),

- distrust in the local authorities ([1:3] the callousness and indifference of others and non-involvement of law), or,

- the existence of personal problems that obviously prevent one from participating in such activities ([1: 4], [1:5], [1:6]).

Table 4. Motivation not to participate in community activities

Quotation Manager [HU: Qual-Analisys-NU] - 13 Codes

\section{Conditioning by results}

[1:11] It depends on the outcome of volunteering.

\section{Distrust in existence of real beneficiary}

$[1: 12]$ I do not trust that the beneficiary of my work is the one initially mentioned

\section{Indifference of beneficiaries}

[1:8] I am not willing to work for others who are doing nothing but only complain and they can not even understand why it happens that someone else is doing something for them. They constantly have the feeling that they deserve that someone should take care of them.

\section{It's not worth it}

[1:13] It is not worth it

\section{Lack of (any) resources}

[1:10] The lack of organization, programmes, time, appreciation, motivation, project completion, confidence, concrete purpose, importance.

\section{Lack of communitarian organization}

$[1: 9]$ When there is an organization in the community which explains everyone what is expected of the community and of each and every person and those who lead the community set their own example, then I will get involved too.

\section{Lack of reciprocity}

[1: 1] As long as the community does not do anything for me, why would I do something for the community?

\section{Lack of respect for social implication}

[1: 7] Volunteering is not respected and appreciated by the vast majority of society members

\section{Lack of trust in local authorities}

[1: 2] I can't boast with a personal contribution to the welfare of the community and the reason why I didn't get involved and I don't intend to do it is the lack of trust in the local authorities which not only do not support such initiatives but also in the few cases when they give their endorsement they do it because they have their own hidden purposes and petty interests.

[1:3] Callousness and indifference of others and non-involvement of law

\section{Personal troubles}

[1:4] I have health problems and do not know how much I could honour a request. [1:5] I'm ill

[1:6] For the moment I can't, I have a young son aged 1 year and 4 months who is keeping me fully occupied.

Source data processing, by the authors, in Atlas Ti

By contrast, volunteering is seen as a state of normality by 9 of the respondents, representing $3.5 \%$ of the total subjects. Following the text encoding, as shown in Figure 6, we find that 4 responses are recorded with dual relationship (the participants in the survey wished to argue their points of view both in terms of satisfactions and achievements obtained as a result of volunteering. Four responses are recorded with one relationship and one response with no relationship (no arguments). 


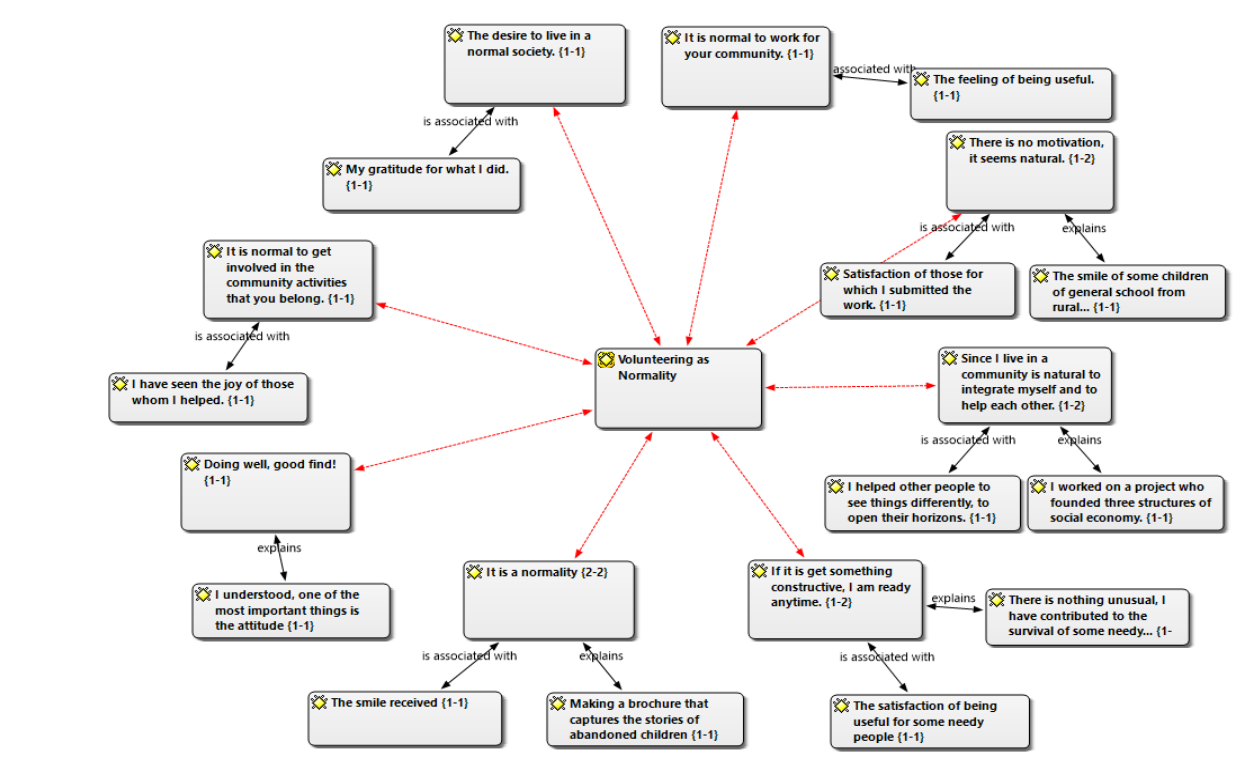

Figure 6. Relations identified in the "Volunteering as Normality" network.

Source data processing, by the authors, in Atlas Ti

Normality is both simply and naturally expressed and eloquently supported with arguments by the participants in the survey: It is a normality ([2.3]), It is normal to get involved in the activities of the community to which you belong ([2.4]), "What goes around, comes around!" ([2.1]), If you get something constructive, I'm always willing ([2.2]), Since I live in a community it is natural to integrate myself and that we should help each other ([2: 6]), There is no motivation, it seems natural ([2: 8]) or, Desire to live in a normal society ([2: 7]), to enumerate just a few examples of responses.

The satisfactions associated with this category of participants in the study, obtained as a result of involvement in community life, are just as normal: the satisfaction of being useful ([2.2]), the smile received ([2.3]), the joy of those whom I helped ([2.4]), the fact that I helped other people to see things differently, to open their horizon, or, my own contentment for what I did ([2: 7]), and the effects of the work done can't be ignored. Thus, by their more or less measurable nature, they can be recognized as moral values, such as, for example:

- I understood that one of the most important things is the attitude you choose when life gives you its challenges. A positive attitude towards everything that is "bappening" is helpful in any situation. ([2.1]); - It was nothing out of the ordinary, I have contributed to the survival of needy people. ([2.2]);

- The smile of some school children from rural areas to whom we provided school supplies, textbooks and auxiliary products ([2: 8]), or simply,

- The feeling of being useful ([2.5]), but also material values, such as:

- Producing a booklet that captures the stories of abandoned children ([2.3]), or establishing social economy structures [2:6])

Community cohesion is the engine that puts into motion 22 of the respondents, representing $8.56 \%$ of all the subjects. These people's motivation to involve in volunteering activities, for the benefit of their communities, is related to:

- the way in which they perceive their relationship with the community (ex .: I am part of 
the community [3:24]; What you wish the people to do for you, do for the people ([3: 1]); if you do not start doing something, do not expect to receive [3: 4]; Because the society in which I live has helped me to develop until now [3: 5]; I care about others and the living environment. Volunteering humanizes us. [3: 9]; People need to help each other and those who have something to offer (not necessarily material) must carry on this gift [3:14]; I know my well-being and that of my children is linked with the welfare of my community. [3:22]);

- the manner in which the relations with the authorities are perceived and ability of the authorities to solve community problems (E.g.: The government will never help us if we don't help ourselves. [3: 8]) and, equally,

- issues related to the role and place that each participant in the study assumes, at some point, in the community (It's important to be responsible and to offer help [3:6] or, I'll be the beneficiary of my work as a member of the community. To give an example to other disinterested people. To change something [3:25] or, By getting involved, something necessary and useful is accomplished and I become an example of involvement, engage other volunteers in this volunteering activity, [3:10]).

The satisfactions obtained by participating in volunteering activities are closely related to the manifestation of community cohesion, such as: The success of the project, through the involvement of a large number of participants. [3:25]; Developing teamwork skills [3:5]; that the help that I offered to some individuals had some results [3: 7]; usefulness [3:10]; my satisfaction that I managed to do something [3:3]; I participated in volunteering activities organised by the school, not by the Bulgarian community in Targoviste city. You feel human, you feel like being part of this world [3:11]; that I did something which contributed to the smooth running of society without receiving material benefits [3:13], and so on.

The effects of volunteering, identified as moral values (sentiments, emotions, beliefs expressed) and material values, also bear the imprint of the solidarity between the organisers of volunteering activities, the beneficiaries and the community. In the life stories offered by participants in the survey we recognize, a great diversity of forms of manifestation of cohesion, especially by means of the trust capital that is invested and "barvested" in a truly collaborative community:

- The feeling that I am part of the construction of life with the beautiful results offered. [3:24];

- I have accomplished myself as a human being in a world with people! [3: 3];

- When others trusted me, invested and were patient, the results were felt in some years and now I wish I can do the same in my turn [3:17];

- My students with precarious social situations were able to complete their studies and find very well-paid jobs. I keep in touch with them constantly, we see each other, we exchange opinions, and we have a friendly relationship. Some of them have became outstanding personalities in their area and some even in the social field [3: 2];

- I participated in local actions of reforestation of the area, through a collective effort. And this is not a story. [3: 6];

- But I have many stories that I would like to write about: campaigns to educate the parents (before they become parents) campaigns to educate women (before they become wives / mothers) campaigns to educate men (before they become men). This is where I think we should start, from the causes, so that we are no longer heartbroken when we go to orphanages, shelters for maltreated women. [3:13];

- I was able to reroute the $2 \%$ tax on the salaries of some employees in large companies towards a foundation established to help the people diagnosed with incurable diseases; Moreover, many managers of these companies were keen on responding to my initiative with substantial donations. [3: 7]; 
- Obtaining sponsorships for endowing two schools with some IT equipment: one in a rural area and another one in an urban area. [3:22];

- Last year we implemented a social economy project in Arad city, a project I was also involved in. I think these tests will change people's perceptions on the help that each person can give to someone close, without having to consume material resources. [3:21].

Usefulness and achieving quantifiable results are two reasons that motivate 31 of the respondents to participate in various activities to the community benefit. The ability to help, assuming the responsibility towards the community, or the emotional ties established with their birthplace, are real and credible reasons that determine these participants in the study to engage in collaborative activities through volunteering (table 5), and the results, quantified as tangible and intangible values, are intended to confer them authority and reputation in the community (even in the society).

Table 5. "Volunteering utility" Category

\section{Motivations for involvement in volunteering activities}

- Capacity to belp [4:2];

- About maximizing the general welfare, no society can achieve its potential in a passive way. Although most would probably prefer that "someone would come and do it", history demonstrates that this was not how the developed societies got where they are [4:7];

- responsibility towards the community in which I work [4:11];

- I'm emotionally tied to the place where I was born and where I live [4:15];

- The community cannot develop in the direction we desire if don't know our wishes and what better way to find out which they are than getting involved and leading things in the right direction [5:2]

- If I'm needed and I can belp, why not!... [5:4]

Satisfactions offered by volunteering

- I could help people who cannot fend for themselves or who are in difficult situations [4:4];

- Scientific promotion of colleagues [4:8];

- The success of the activities I was involved in and the joy of those who have received my help [4:14];

- The feeling of doing something for someone, being able to be belpful [5:2], or

- the joy to share my knowledge with others [5:4].

Results obtained

- a legal system, [4:8];

- the children from Zlagna school, Sibiu county, following the mobilization with their high school classmates, received clothes and food, as well as a fully equipped computer lab, [4:12];

- Undoubtedly, the most beautiful story is the "Equality and non-discrimination" contest, designed together with colleagues from the CNCD and ISMB. The joy of the children who came to receive their prizes (especially those from Bărăganu commune, Constanta county) was extraordinary. I'm also glad for their (unique) joy., [4:14];

- I belped a child to benefit from special treatment. He is autistic and his parents didn't have the means to finance bis treatment. I did this by contacting acquaintances from the businesses environment and colleagues to redirect 2\% of income tax [4:15];

- As a teacher, any progress, however small, of a student you coordinated is a beautiful story. [5:5];

- I do not think that there is a more beautiful story than life! Especially when from a young age you are willing to assume all the possible social roles - daughter, mother, employee, friend, mentor, manager, good neighbour real multi-tasking. And almost all worked out well for me - God, I'm so modest! [5:6];

- the most beautiful story work for the benefit of the community so that that place would look better, [5:7];

- building a church, through my own forces, in the town where I was born, given that in that place there was only a parochial bouse [5:10].

Source data processing, by the authors, in Atlas $T i$

The range of outcomes of the volunteering activity, as presented by the participants in the study, is very diverse, from providing schools with the necessary goods for performing the 
act of education in optimal conditions, to the creation of a legislative system or the construction of a church (by one's own forces) (Table 5). We observe that the responses recorded in Table 5 (which are presented in their original form, without even having intervened on the spelling) the naturalness of thought, of the feelings expressed by the respondents, of their language, but also the absolute freedom of expression (I do not think that there is a more beautiful story than life! Especially when from a young age you are willing to assume all the possible social roles - danghter, mother, employee, friend, mentor, manager, good neighbor real multitasking. And almost all worked out well for me - God, I'm so modest! [5:6]).

Some participants in the study, 16 subjects, are attracted to volunteering by the desire to do something to benefit the community. The progress of the community, or certain punctual needs such as: the community need to be helped, the need for culture and education, or the fact that the people have some current needs that the community can't satisfy, are as many reasons for social involvement through volunteering (Table 6). The satisfactions of this category of participants in the study, coming from their involvement in the community life, are given by the feeling of being part of solving the problems, in fact of covering the specific needs of each community: participation in setting up a botanical garden, the development of studies and research, support for disadvantaged people, etc. The community can enjoy a post-secondary sanitary school, counselling for autistic children, a cleaner environment, the existence of cohesive teams able to expeditiously respond to requests, all this as a result of voluntary work (Table 6).

Table 6. "For the community benefit" Category

\begin{tabular}{l}
\hline Motivations for involvement in volunteer activities \\
\hline - The community needs help [8:7]; \\
\hline - Not always does the community meet the current needs of the people [8:9]; \\
- to cover the need for education (culture) of the community [8:10]; \\
\hline - Vocation for social assistance [8:19]; \\
\hline - So that the community I come from can progress [8:12];
\end{tabular}

Satisfactions offered by volunteering

- Participation in setting up the botanical garden in Bucov [8:6];

- development of scientific studies, papers and specialized treatises [8:10];

- I experienced a series of satisfactions, but the biggest one may be an increase in the level of self-confidence, [8:14];

- to support the community that I belong to with a view to improving the living conditions and offering new opportunities to disadvantaged people or to those who belong to vulnerable groups, [8:16];

- the trees which were planted, and which I have seen growing, [8:17];

- Direct knowledge of community needs and the joy of giving joy [8:19]

\begin{tabular}{l}
\hline Results obtained \\
- Making an apartment belonging to the orphanage St. Andrew Ploiesti for counselling children with autism and volunteers from \\
the Ploiesti city prison, [8:8]; \\
\hline - Establishment of the "Thoma Ionescu" Post-Secondary Sanitary School [8:6]; \\
- Participation in reclaiming the Rosioara brook [8:9]; \\
- I have lived many beautiful stories in my social involvement but the most beautiful of all is the successful establishment of a \\
foundation and the continuity of its activity [8:14] \\
- I managed to participate in the marathon $(21 \mathrm{~km})$ and the money I won was used for charity (in bospitals) [8:17] \\
- training courses beld in an NGO [8:16] \\
- Building a team with the same vocation as mine, where I grew up until the level at which our existence and our opinion counts (at least \\
in some circles). The first projects are the most dear and once you gain the experience you become efficient and the results are easily visible. \\
It's nice that at the beginning we were giving food to the poor elderly and now, after 20 years, we are still doing it. [8:19]
\end{tabular}

Source data processing, by the authors, in Atlas Ti 
The desire for social change is another motivation for involving in volunteer activities that characterizes 12 of the subjects; some of them want that they should be the change they want from the community (ex.: If you want change, you have to get involved [9: 3]).

Analysing the responses recorded in Table 7 we find that the need for profound social changes or changing mentalities are very strong motivations for getting involved in voluntary activities (Only in this way do we have a chance to recover as a nation and to leave something valuable (principles, models, etc.) to our children [9:11]; or, When you reach a certain level of personal and professional development you seek satisfaction elsewhere. On the other hand the mentality of civil servants and also the mentality of assisted persons must be changed somehow [9:1]).

The satisfactions offered by the work arise from finalising the undertaken actions: positive feedback from beneficiaries, pupils who successfully complete their studies and integrate in the community, positive changes, but also The fact that other participants understood, just like me, that this work must be done! Then, the fact that the result of our work should be useful to each member of the community and to the community itself. Then, the respective participation should be a role model for the other members of society who have not yet decided to participate and at the same time, a satisfaction that society is making a social and even an economic progress, [9:9];

The work results reported in Table 7 are quantified like: cultural activities that promote the community and keep the community spirit alive, the changes made in the community, the further development of the society and, last but not least, perpetuating the practice of helping, of assisting the community (e.g. a former pupil is a manager at Oracle Romania and organizes visits for high school pupils in this centre, to belp them understand what can help them in the future... [9:6]).

Table 7. "Social changes" Category

Motivations for involvement in volunteer activities - Ifyou want change, you must get involved [9:3];
- When you reach a certain level of personal and professional development you seek satisfaction elsewhere. On the other hand the
mentality of civil servants and also the mentality of assisted persons must to be changed somehow [9:1];
- evolution, in all its forms [9:5]
- Together we can bring about change [9:7];
- Only like this we have a chance to recover as a nation and to leave something valuable (principles, models, etc.) to our children
[9:11];

- For a more civilised society [9:12]

Satisfactions offered by volunteering

- I know I could belp a less fortunate soul, [9:3];

- I think through such actions something changes to the better in each of us, every time: we give and we don't expect anything in exchange, [9:5];

- Since my students are encouraged to learn as many things as possible from many fields, they find very good jobs and keep in touch with me even after 20-25 years and from different parts of the world, [9:6];

- The fact that other participants understood, just like me, that this work must be done! Then, the fact that the result of our work should be useful to each member of the community and to the community itself. Then, the respective participation should be a role model for the other members of society who have not yet decided to participate and at the same time, a satisfaction that society is making a social and even an economic progress, [9:9];

- The joy of the people I worked for and helped, [9:14];

- The feeling that I have done something useful, [9:16];

- positive reactions of the people / target groups [9:15];

\section{Results}

- The most beautiful story is that of my pupils: e.g., a former pupil is a manager at Oracle Romania and organizes visits for bigh school pupils in this centre, to help them understand what can help them in the future. Several former pupils work for big 
companies, several are free-lancers in IT and can manage particularly well, [9:6];

- Changing several children and motivating them [9:7];

- It makes no sense to write literature or magazine articles here, but I know I belped elderly people to survive (I took care of them, I accompanied them to the doctor, I supported them financially, morally and so on), I helped youth, especially pupils, which at one time were 'trying out' a juvenile delinquency, I helped people who indicated they needed some support. The most precious involvement for me was, $i$, and will be the attitude towards anything and anyone; I will care for anything that might happen next to me, no matter for how long that something may last, [9:9];

- material and moral support for the organisation of the 6th edition of the Popular Patriotic Song National Festival - August 15, 2016 at Oarba de Mures [9:10];

- I offered material support to a pupil who lived outside the town to come to school, for the entire school year [9:16]

- Development of the society, year by year [0:13]

Source data processing, by the authors, in Atlas Ti

Some participants in the study stood out as people living for the children and through the children, their motivation for getting involved in volunteering being as generous as possible: investment in "tomorrow's generation".

The motivations of this category of subjects to involve in volunteer activities are supported by arguments such as: - I have succeeded and I also wish others to succeed, so that the next generation would no longer want to leave the country, but to believe that here it is also possible, [6: 5]; $A$ better and more beautiful life for the children in our community. [6:10]; I am! And as long as I am, I interact with the people and their needs [6:12]; or simply: why not? [6:3]. It is obvious that these motivations underly the decision to carry out community service.

The satisfactions of these subjects relative to the work carried out within and for the community are also quantified as benefits for the community, coming from seemingly trivial actions, as a result of the interaction among the people, such as: - permanent interaction with living human beings, [6:12]; - I had the satisfaction that something useful was achieved for the community with my support [6:11]; - the feeling that I am doing something useful and that I am helping others [6: 9]; - children who, as they grow, they remember the different activities that we did together. Very special, I feel fulfilled when I see some of these children carry on the story we started together [6: 3]; - working with children and adolescents; the gleam in their eyes, in the moments when they successfully managed to perform the proposed activity [6: 1].

The results obtained stand out both due to the emotional load transmitted by the participants in study in their life stories, which reflect how the children they interacted with were changed, such as: - the clear and bright eyes of the children arrived at adulthood, whom I had guided just a few years before. [6: 1]; - there are many ... but the nicest is the clear eyes of a buman being with whom you interacted trying to solve different life situations. [6: 3]; - A lifetime in the household for the upbringing and education of the children so that they surpass the social status I had [6: 8]; - I helped a group of children to face the reality, to stand face to face with their personal reality and finally to take the decision that each of them considered correct at that time. This may be fair, because those children, now adults, remember with pleasure those moments and share them with me whenever we meet. [6:12].

Beyond these emotions, we find that the outcomes of involving these subjects in the community life have a special concreteness, they are meant to change destinies, thanks to the access to education granted to a category of disadvantaged people, and the examples are as varied as they are conclusive, beginning with the aid received by young people to follow their path in life, to projects designed to save lives:

- I helped a talented young woman to obtain a faculty degree that she wouldn't have had the chance to 
obtain otherwise [6: 2];

- a total number of about 30 children who learned to play instruments, a real orchestra now. [6: 4];

- providing aid to young people to complete their studies and find jobs. Being appreciated and advancing rapidly where they were employed. They brought added value to the company through their involvement [6: 7];

- I have prepared children devoid of means for the baccalaureate and I felt really good when they had good results [6: 9];

- I was involved in a project entitled "Be cautious, give life a chance!", and at the end I had the satisfaction that, through the advice given to the participants in project (from several schools) I could save at least one LIFE - if each one was cautious and followed the indications from my experience [6:11];

As a matter of fact, it is quite obvious that the community is the one who benefits from the change for the better of people's destinies, due to the direct (especially economic) and indirect effects, to the transformation of mentalities and attitudes that leads to progress.

The last category of answers that we are analysing is that of the subjects who engage in volunteering for self-realization or for the desire to give meaning to their lives. Satisfaction, contentment, respect, recognition and willingness to help are as many motivations, but also sources of personal satisfaction for this category of participants in the study, in terms of community involvement (table 8).

Table 8. "Self-realization, the fulfilment of their own lives" Category

Motivations for involvement in volunteer activities

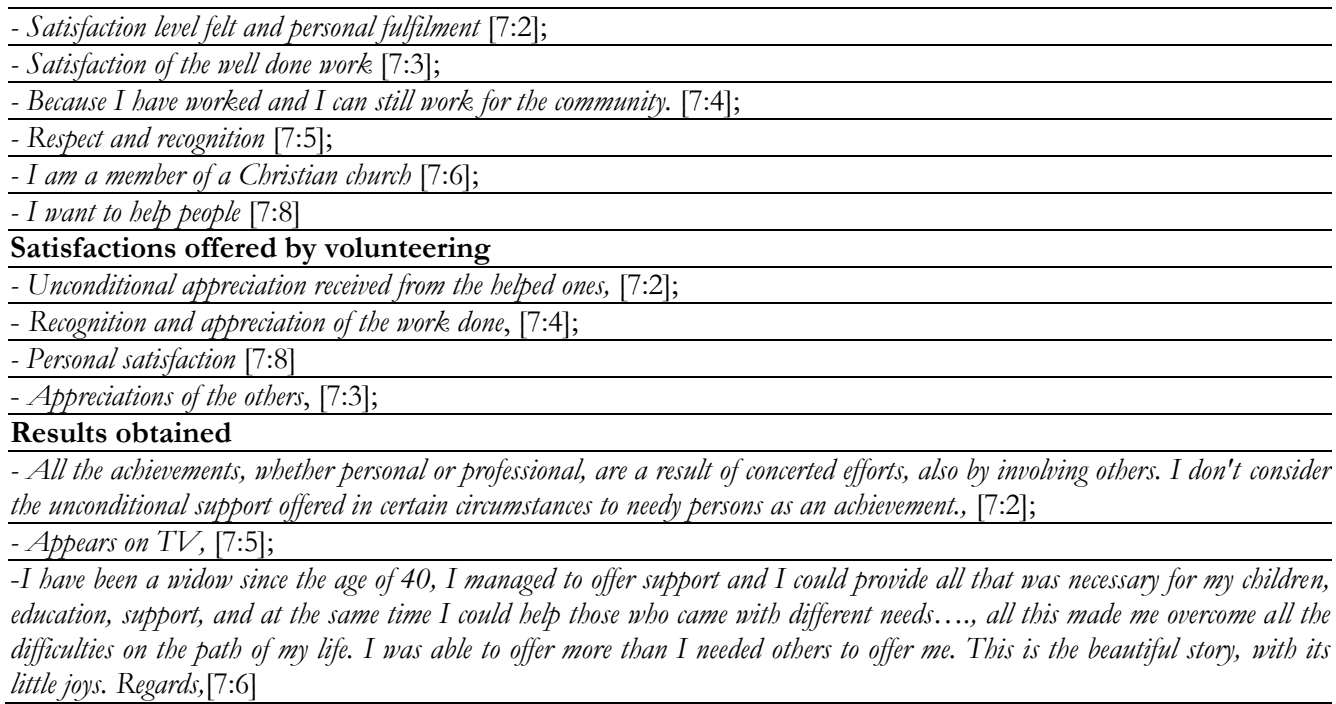

Source: data processing, by the authors, in Atlas Ti

\section{Conclusions}

The questions we asked before the beginning of the study (Which are the tangible and intangible effects of the acts and facts of the collaboration identified in your community?) and, (How are the collaborative volunteering activities recorded in the collective memory of Romanian communities?) have 
found a lot of answers in the experiences of the participants in the study. This shades the nature of collaboration in local communities (schools, hospitals, orphanages, homes for the elderly, etc.).

The qualitative, exploratory analysis undertaken highlights the role of volunteering as a factor of collaboration and, simultaneously, as a collaborative practice in Romanian local communities. The voluntary work carried out by the participants in the study, their personal motivations, satisfactions and results obtained remain imprinted in the collective memory of the community thanks to the newly created attitudinal, creative and experiential values. From the experiences shared by the participants in the study, the collective memory contains a clear past volunteer work - by the fact that many people's destinies have been changed, a concrete present - indicated by the tangible achievements, as well as a foreseeable future - through the continuity and perpetuation of the activities started.

Using paid work and volunteering is one of the distinguishing features of social economy enterprises, which has stirred our interest in carrying out an in-depth analysis of the effects of volunteering in local communities. At the same time, besides the economic role that it assumes within the community, the social economy enterprise has a strong role of facilitator of interpersonal relationships and volunteering is the glue that brings together and creates connections between the social actors, the providers and beneficiaries of prosperity, contributing in a concrete manner to creating collaborative communities.

As such, the collaborative community is looming as a sustainable solution for the successive economic and social crises that we have been going through for more than a century. This is at least one of the reasons why we consider it useful to continue the theoretical and applied research related to the emergence of collaborative communities.

Regarding the theoretical and methodological approaches whose object of study is the collaborative community, we have already noted that they are in the infancy stage. At least as long as there are less than 50 papers (articles, books, etc.) identified in the stage of documentary research, in the relevant databases worldwide (Google Scholar and Scopus) developed in the management area of interest. Since "the field" of research having collaborative community as its object of study is empty, it is obvious that we can invoke a second reason why we consider it very useful to continue the research on collaborative communities.

We have not identified any scientific papers on the topic of collaborative communities written by Romanian authors or which refer to situations in Romania, so we consider our work as pioneering for Romanian and international research, and this is the third reason why, as Romanians, we consider it is useful to continue the research in the collaborative communities study area.

Without exaggerating the role of volunteering, but recognizing its role as a forger of relationships in a community, we intend to expand the field of investigation towards designing a new model of social economy enterprise, where the volunteer is at the core of a collaborative network.

\section{References}

Brudney, J.L.; Meijs, C.P.M.L. Models of Volunteer Management: Professional Volunteer Program Management in Social Work. Human Service Organizations: Management, Leadership \& Governance, 2014, 38/(3): 297-309, Routledge, Taylor \& Francis Group, ISSN: 2330-314X, DOI: $10.1080 / 23303131.2014 .899281$ 
Sherr, M. L. Social work with volunteers. Lyceum Books, Chicago, 2008

Wollebaek, D; Selle, P. Does Participation in Voluntary Associations Contribute to Social Capital? The Impact of Intensity, Scope, and Type. Nonprofit and Voluntary Sector Quarterly, 2002, 31/(1): 32-61, Sage Journals, ISSN: 1552-7395, Available online: http://doi.org/10.11 77/0899764002311002, (accessed on 13 November 2017)

Carvalho, M.S.; Maghalhaes, D.; Varela, M.; Sa, J.; Gonçalves, I. Definition of a Collaborative Working Model to the Logistic Area Using Design for Six Sigma. International Journal of Quality and Reliability Management, 2016, 33/(4): 465-475, ISSN: 0265-671X, Available online: http://doi.org/10.1108/IJQRM-11-2014-0190, (accessed on 13 November 2017)

Gadman, L.J. Open source leadership: Leading and managing community led programmes to support strategies for next generation broadband implementations across Europe. International Journal of Organizational Analysis, 2013, 21/(4): 528-545, ISSN: 1934-8835, Available online: http://doi.org/10.1108/IJOA-03-2012-0571, (accessed on 13 July 2017)

Wu, H. Social Impact of Volunteerism. Points of Light Institute, New York, 2011, Available online: https://www.pointsoflight.org/sites/default/files/site-content/files/social_impact_of _volunteerism_pdf.2011/8/30, (accessed on 15 November 2017)

Stephenson, K. The changing face of volunteering and four ways you can respond. National Council for Voluntary Organisations (NCVO), ISBN: 978-0-7199-0025-9, Available online: https:// www.blogs.ncvo.org.uk/2017/02/10/the-changing-face-of-volunteering-and-four-ways-you-canrespond/, (accessed on 12 November 2017)

Mills-Dick, K.; Hull, J.M. Collaborative research: Empowering students and connecting to community. Journal of Public Health Management and Practice, 2011, 17/(4): 381-387, ISSN: 1078-4659, DOI: 10.1097/PHH.0b013e3182140c2f

Jensen, C.D. Action Research to Support Development Of Engineering For Sustainable Development Degree Programs, Part I: Collaborative Community Action Research Vignettes. Journal Of Cleaner Production, 2016, 122: 164-175, ISSN: 0959-6526, DOI: 10.1016/ /j.jclepro.2015.09.088

Siedlok, F.; Hibbert, P.; Sillince, J. From Practice to Collaborative Community in Interdisciplinary Research Contexts. Research Policy, 2015, 44/(1): 96-107, ISSN: 0048-7333, Available online: htpp://doi.org/10.1016/j.respol.2014.07.018, (accessed on 17 July 2017)

Ruberg, L.F.; Cummings, M.; Piecka, D.C.B.; Ruckman, C.; Seward, R. A Logical Approach to Supporting Professional Learning Communities. Knowledge Management And E-Learning, 2011, 3/(4): 599-620. ISSN: 2073-7904, Available online: https://www.kmel-journal.org/ojs/ index.php/onlinepublication/article/viewFile/150/117, (accessed on 14 November 2017)

Schafer, W.A.; Carroll, J.M.; Haynes, S.R.; Abrams, S. Emergency management planning as collaborative community work. Journal of Homeland Security and Emergency Management, 2008, 5/(1): 1-17, ISSN: 1547-7355, Available online: http://doi.org/10.2202/1547-7355.1396, (accessed on 17 July 2017)

Snow, C.C. Organizing In the Age of Competition, Cooperation, and Collaboration. Journal of Leadership and Organizational Studies, 2015, 22/(4): 433-442, ISSN: 1548-0518, DOI: 10.1177/ $/ 1548051815585852$

Snow, C.C.; Fjeldstad, O.; Lettl, C.; Miles, R. Organizing continuous product development and commercialization: the collaborative community of firms model. Journal Of Product Innovation Management, 2011, 28/(1): 3-16, ISSN: 1540-5885, DOI: 10.1111/j.1540-5885.2010. 00777.x

Kuehnert, P.; Graber, J.; Stone, D. Using a web-based tool to evaluate a collaborative community health needs assessment. Journal of Public Health Management and Practice, 2014, 20/(2): 175-187, ISSN: 1550-5022, DOI: 10.1097/PHH.0b013e31829dc1e5

Caldwell, C.H.; Zimmerman, M.A.; Isichei, F.P.A. Forging collaborative partnerships to enhance family health: an assessment of strengths and challenges in conducting community -based research. Journal of Public Health Management and Practice, 2001, 7/(2): 1-9, ISSN: 1078- -4659, Available online:

http://journals.lww.com/jphmp/2001/07020/Forging_Collaborative _Partnerships_To_Enhance.3.aspx (accessed on 9 July 2017)

Crossman, J.M.; Kite, S.L. Their Perspectives: Esl Students' Reflections on Collaborative Community Service Learning. Business Communication Quarterly, 2007, 70/(2): 147-165, ISSN: 1080-5699, DOI: $10.1177 / 1080569907301776$

Kendall, E.; Muenchberger, H.; Sunderland, N.; Harris, M.; Cowan, D. Collaborative capacity building in complex community-based health partnerships: a model for translating knowledge into action. 
Journal of Public Health Management and Practice, 2012, 18/(5): E1-E13, ISSN: 1078-4659, DOI: 10.1097/PHH.0b013e31823a815c

European Commission. Social economy and social entrepreneurship. Social Europe guide. 2013, 4: 4, ISBN: 978-92-7926866-3, DOI: $10.2767 / 79109$

Defourny, J.; Nyssen, M. Social enterprise in Europe: recent trends and developments. Social Enterprise Journal, 2008, 4/(3): 202-228, ISSN: 1750-8614, Available online: http://doi.org/ /10.1108/17508610810922703, (accessed on 13 November 2017)

Casey, J. Comparing Nonprofit Sectors Around the World: What Do We Know and How Do We Know It? Journal of Nonprofit Education and Leadership, 2016, 6/(3): 187-223, ISSN: 2157-0604, Available online: http://dx.doi.org/10.18666/JNEL-2016-V6-I3-7583, (accessed on 13 November 2017)

European Commission - Growth: Internal Market, Industry, Entrepreneurship and SMEs. Available online: http://www.ec.europa.eu/growth/sectors/social.economy/enterprises_en (accessed on 12 November 2017)

Alexander, J.A.; Comfort, M.; Weiner, B.; Bogue, R. Leadership in collaborative community health partnerships. Nomprofit management and leadership, 2001, 2: 159-175, ISBN 978-078-796-033-9, DOI: $10.1002 / \mathrm{nml} .12203$

Leonard L.J. Schools as professional communities: Addressing the collaborative challenge. International Electronic Journal for Leadership in Learning, 2002, 6:1-21, ISSN: 1206-9620, Available online: http://ucalgary.ca/ iejll/volume6/leonard.html (accessed on 9 July 2017).

Barker, J.R. (reviewer); Heckscher, C.; Adler, P.S. The Firm as a Collaborative Community. Administrative Science Quarterly, 2007, 2: 328-330, ISSN 0001-8392, WOS: 000249582900006

Perrow, C. The firm as a collaborative community: reconstructing trust in the knowledge economy. Academy of Management Review, 2008, 3: 778-782, ISSN 1930-3807, DOI: 10.5465/ AMR.2008.32465777

Jianyuan, L. Organizational Model of Distributed Innovation: A Collaborative Community. Contemporary Economy \& Management, 2011, 12: 29-36, ISSN 1673-0461. Available online: http://en.cnki.com.cn/Article_en/CJFDTOTAL-DJGL201112007.htm (accessed on 19 June 2017)

Cheng, A.; Sturtevant, V. A framework for assessing collaborative capacity in community -based public forest management. Environmental Management, 2012, 3: 675-689, ISSN 0364-152X, DOI: 10.1007/s00267-011-9801-6

Jenkins B., Henley G. Collaborative management: community engagement process as the decision making process. Christchurch, University of Canterbury, 2013. Available online: https://ir. canterbury.ac.nz/bitstream/handle/10092/9085/12646429_Copy\%20of\%20Revised\%20paper\%2 017\%206\%202013.pdf?sequence $=1$ \&isAllowed $=y$ (accessed on 10 November 2017)

Kim, S. The Relationships Between Process and Outcome of Collaborative Community Governance: A Path Analysis. Journal of the Korean Urban Management Association, 2015, (28) /3: 163-195, ISSN 1598-8686, KJD: ART002038672. Available online: http://www.dbpia.co.kr/ Journal/ArticleDetail/NODE06523467 (accessed on 7 November 2017)

Del Chiappa, G.; Atzeni, M.; Ghasemi, V. Community-based collaborative tourism planning in islands: A cluster analysis in the context of Costa Smeralda. Proceedings of the $6^{\text {th }}$ Advances in Tourism Marketing Conference "Tourism Engagement: co-creating weel-being", Journal of Destination Marketing \& Management, 2016, ISBN: 978-952-61-1861-1, Available online: https://iris.uniss.it/handle/11388/75244\#.WgAYymiCyvM (accessed on 9 November 2017)

Mook, L.; Handy, F.; Schugurensky, D.; Quarter, J. Degree and direction of paid employee/ volunteer interchange in nonprofit organizations. Nonprofit Management and Leadership, 2013, 23/(4): 409-426, ISSN: 1542-7854, DOI: $10.1002 / \mathrm{nml} .21072$

Boudreau, K.J.; Lakhani, K.R. Using the Crowd as an Innovation Partner. Harvard Business Review, 2013, 4, 60-69, ISSN 0017-8012, WOS: 000316518000036

Hatzi, O.; Meletakis, G.; Katsivelis, P.; Kapouranis, A.; Nikolaidou, M.; Anagnostopoulos, D., 2014. Extending The Social Network Interaction Model To Facilitate Collaboration Through Service Provision. In Springer Proceedings of The $15^{\text {th }}$ International Conference, BPMDS 2014, 19th International Conference, EMMSAD 2014, Held at CAiSE 2014, Thessaloniki, Greece, June 1617, 2014, 94-108 
Li, E.Y.; Loh, S.; Evans, C.; Lorenzi, F. Organizations And Social Networking: Utilizing Social Media To Engage Consumers. IGI Global, Washington D.C., USA, 2013, ISBN 978-146-664-026-9, DOI: $10.4018 / 978-1-4666-4026-9$

Kathan, W.; Hutter, K.; Füller, J.; Hautz, J. Reciprocity vs. Free-Riding in Innovation Contest Communities. Creativity And Innovation Management, 2015, 24/(3), 537-549, ISSN (online): 1467-8691, DOI: 10.1111/caim.12107

Adler, P.S.; Kwon, S.; Heckscher, C. Professional Work: The Emergence of Collaborative Community. Organization Science, 2008, 19/(2), 359-376, ISSN (online): 1047-7039, DOI: 10.1287 /orsc.1070.0293

Frieling, M.A.; Lindenberg, S.M.; Stokman, F.N. Collaborative Communities Through Coproduction: Two Case Studies. American Review Of Public Administration, 2014, 44/(1), 35-58, ISSN (online): 02750740, DOI: $10.1177 / 0275074012456897$

Blake, D.; Cucuzza, T.; Rishi, S. Now or Never: The Automotive Collaboration Imperative. Strategy \& Leadership, 2003, 31(4), 9-16, ISSN: 1087-8572. Available online: https://doi.org/ 10.1108/10878570310698359 (accessed on 10 November 2017)

Weinberg, B.D.; De Ruyter, K.; Dellarocas, C.; Buck, M.; Keeling, D.I. Destination Social Business: Exploring an Organization's Journey with Social Media, Collaborative Community and Expressive Individuality. Journal Of Interactive Marketing, 2013, 27/(4), 299-310, ISSN (online): 1094-9968, DOI: 10.1016/j.intmar.2013.09.006. Available online: https://ac.els-cdn.com/S1094996813000418/1s2.0-S1094996813000418-main.pdf?_tid=4b939ce2-c381-11e7-bb d300000aacb362\&acdnat $=1510034754 \_4374 \mathrm{~cd} 0 \mathrm{cca} 432 \mathrm{dafb} 28 \mathrm{~d} 0 \mathrm{ada} 26822 \mathrm{bf} 8 \quad$ (accessed on 10 November 2017)

Putman, S.M.; Cassady, J.C.; Smith, L.L.; Heller, M.L. Removing Barriers: Using a Pds Model to Enable Collaborative Community and School Partnerships to Serve At-Risk Students. Professional Development and Workplace Learning: Concepts, Methodologies, Tools, and Applications, 2015, 12, 157-174, ISBN: 978-1466663671, Hershey, PA: IGI Global, DOI: 10.4018/978-1-4666-6367-1.ch012

Githens, R.P. Leadership and Power in Fostering a Collaborative Community In a Non-Profit Professional Organization. Systemic Practice and Action Research, 2009, 22/(5), 413-429, ISSN: 1573-9295, DOI: 10.1007/s11213-009-9138-8. Available online: https://doi.org/10.1007/ s11213-009-9138-8

Moscovici, S.; Buschini, F., 2007, Methodology of socio-human sciences. Polirom, Iași, Romania (In Romanian) Clocotici, V., Stan, A., 2000, Applied Statistics in Psychology, Polirom, Iași, Romania (In Romanian) 